that resolution may differ widely from country to country. For example, as the book points out in chapter five, Canadian women of South Asian origin with a cultural bias against female children may obtain a termination of pregnancy in that country, provided that the physician is unaware that this is a sex selection preference. These same women can, and do, cross the border into the USA where a termination of pregnancy due to parents' preference is not an issue. In the UK, it may well be that some ethnic groups might also choose to discriminate against female babies - it is certain that national sentiment would not support them.

This book clearly makes the point about nationalicultural differences. It compares and contrasts the legal 'ethical positions in the UK with those in France in particular, and in the EU/USA in general. It is noteworthy that some chapters in this book refer to "England". If this is simply a loose way of describing the United Kingdom, then it is merely irritating. But if it is describing English Law, then this lack of clarity could be significant. One of the clearest contrasts is in the approach to surrogacy. In France, it is prohibited - in the UK it is regulated.

This is not to say that all interested parties in the UK are in agreement. Those who feel that France has chosen the better path will be encouraged by the words of Sir Malcolm Macnaughton, former president of the Royal College of Obstetricians and Gynaecologists (RCOG), who in a paper published in the November 1997 issue of the fournal of the British Fertility Society wrote: "The Ethical Committee of the International Federation of Obstetrics and Gynaecology had strong reservations about the practice of surrogacy and was concerned that it might violate family values. Children born into situations where their genetic, gestational, and social relationships to their parents are fractured, are at potential risk and would best be served by policies designed to discourage the practice.

“.......... all decisions .........should be viewed from the perspective of a child's best interests, even, if necessary, at the expense of the interests of the adult parties".

This book does give space to the views of the "adult parties" or "patients", but only in a short chapter written from a French perspective. It would have been helpful to have had a contribution from a UK patients' association. Furthermore, this brief chapter scarcely touches upon the huge variety of fears, doubts, hopes, and dreams of patients undergoing fertility treatments. Most pertinently, in a book about ethics, this book overlooks the possibility that in their overwhelming desire for a child, the prospective parents may ignore or even knowingly reject the ethical dimensions of the treatment they seek. In such cases, ethical input will only be offered by the medical practitioners closely involved, which makes even more important and urgent the need for a clear and coherent approach to these ethical dilemmas within the medical profession.

LESLEY REGAN AND ELINOR JAMES

Department of Obstetrics and Gynaecology, ICSM at St Mary's Hospital, Norfolk Place, London W2 1PG

\section{Fragmentation and Consensus: Communitarian and Casuist Bioethics}

Mark G Kuczewski, Washington DC, Georgetown University Press, 1997, 177 pages, US $\$ 55.00$.

The world of medical practice, understood as a socially situated craft, has seemed ideally suited to the resurgence of neo-Aristotelian ethics in the last two decades of this century (and indeed, on some accounts is partly responsible for it). The renewed emphasis on phronesis, ie the use of practical wisdom and judgment in assessing the particular, is widely agreed to be beneficial: where controversy persists, however, is around the need for agreement on human good(s) or the human end(s).

In this interesting and insightful book, Mark Kuczewski maintains that a form of communitarian casuistry which specifically excludes overall agreement as to the human telos provides the best method available for deliberation in bioethics. Principlebased deontologic models of ethics are rejected as failures, representing to him merely the safeguarding of personal preferences, and leading to interminable debate. His emphasis on consensus as the major goal of ethics is clear throughout his writing.

His outline and critique of varying accounts of communitarianism and casuistry are the core of this work, and succeed superbly in demonstrating which problems in post-
Enlightenment morality such approaches have attempted to address. $\mathrm{He}$ incisively elucidates what he describes as the "whole tradition" model of communitarianism (associated most clearly with Alasdair MacIntyre's more recent writing) with its specific standards of rationality intrinsic to the community's traditions. This he rejects, contrasting it with the "mutual self-discovery" model which attempts to combine the view of humans as both deliberating and social beings, without postulating a shared vision of the good life. Both approaches aim at seeing the moral agent in a situated role in family and society; although Kuczewski is aware of the risks of imposing "shared" values to which even the second approach is prone, he considers that this risk can be met adequately by infusing this model with casuistical methodology. Here, he provides what I consider to be the best critical summary currently available of the origins and method of modern bioethical casuistry, and of its ability (through what he refers to as kinetic taxonomy, ie a changeable under standing of which concepts fit bes with each type of case) itself to critique ethical theory. He thus arrives at specific understanding of communi $=$ tarianism, in which casuistical methods are an integral part. I believe he demonstrates well that the opposition between the two approaches (the one supposedly relying on a "top-down" application of theory to practice, the other moving "bottom-up" from actual decisions in paradigm cases) is only apparent and never has been real. Casuistry can always be understood as a communitarian ethic: whether in its previous historical guises, or as currently used in medical ethics, it only makes sense against the background of a community's practices and convictions. Kuczewski constantly refers to such concepts as "our society" and "our intuitions": casuistry is merely the paradigm-based working out of these societally developed (and thus arbitrary) convictions.

Unfortunately, in attempting to demonstrate the usefulness of "communitarian casuistry" in clinical medical ethics he is much less convincing. His three examples of supposed problems are, to my mind, poorly chosen and fail to show a conceptual or practical advantage for his approach. In the first two, the attempt is merely to illustrate how his approach provides better justification for the current clinical consensus. In considering respect for advance directives to refuse 
treatment if permanently disabled, he has an issue where ready support from all, and no theory, is available. The advance directive demanding all possible treatment regardless of estimated chance of recovery represents a much more problematic case, and one where it is hard to see communitarian respect for the socially based, narrative continuity of human life being able to provide any decisive help. In the second problem, he restricts his analysis to justifying the role of close family members in medical decision making by an adult, competent patient. $\mathrm{He}$ makes clear that the process of informing and consenting is an ongoing voyage of discovery by patients, their care-givers, and their intimate associates (family and friends) in the light of changing circumstances and uncertain results, which fits very well with his "mutual self-discovery" approach. What is not clear, however, is how such an understanding differs from any but the most impoverished principle-based or individual rights model. His third example is that of a comatose young man whose Jehovah's Witness mother claims would refuse blood transfusions, but who has not recently been active in the religious community and who carries no advance directive wallet card. Here, Kuczewski admits he cannot resolve the conflict between casuist and communitarian approaches. Furthermore, his emphasis on the person's narrative identity as his/her legacy leads him to a level of support for the mother's decision which is based more on the family's interpretation of that legacy, than any knowledge of the patient or appreciation of his interests. Here I find his arguments deeply unpersuasive.

While acknowledging that a community of some sort is indispensable for all human beings, and that its many beneficial effects are clear, we must not lose sight of how its prejudices and assumptions can harm individuals. Deciding what is a just and merciful community, given our current institutions and understanding, is a complex issue which requires a great deal more attention than how to explicate and justify areas of current moral consensus. The aim of providing an account of human beings which accepts both their individualism and their situation in concrete ways of life is only partially met by this book. But it is an important step forward in its account of the development of some neoAristotelian approaches in medical ethics, and will be an invaluable resource even for those who, like myself, reject the author's central thesis, and seek to employ both abstract conceptions of inclusive universal principles, as well as careful judgment in their application to actual cases.

GAYLE RAWLINGS

PhD Candidate, Department of Philosophy, University of Cambridge

\section{Ethics of Psychiatry}

\author{
R E M Edwards, New York, \\ Prometheus Books, 1997, 550 pages, \\ $£ 23.00$.
}

Any anthology is likely to have its idiosyncrasies, and this is not necessarily a bad thing. R E M Edwards has collected together 31 essays which address, in different ways, and with different views, some of the commonest ethical dilemmas in psychiatry. The essays are divided into seven sections, each with a useful introduction, and an equally useful list of papers for further reading. One of the strengths of the book is the presentation of the original texts, often appropriately shortened or edited for simpler reading. Reading an author's original arguments is valuable for students, because both the weaknesses and coherence of his or her arguments are easier to read than accounts by either detractors or apologists.

It is thought-provoking to consider which papers one would choose if compiling a similar book (remembering that Edwards co-ordinates a teaching programme in medical ethics, for which this book is designed to be a core text). Edwards's established views about rationality and mental illness clearly influence the tone of the introductions, the choice of papers, and the book's construction in total. The first section addresses conceptual issues in mental health, and especially the evaluative aspect of diagnosis. Here we find classic essays by Szasz and Edwards. The second section contains essays which demonstrate the limitations of the medical model in psychiatry; for example in relation to issues of gender, and erotic object choice. Other sections consider the duties of psychotherapists, and the question of civil commitment. Refreshingly, there is a section about forensic psychiatric dilemmas, although nothing about the involvement of psychiatrists in the death penalty process, which is curious given the emphasis on US law.
The bias I detect is an emphasis on mental illness as a lack of rationality, and rationality itself defined very cognitively. The chief criterion of mental health which is presented is that of a somewhat individualistic and atomistic autonomy. Clearly this vision of autonomy has an evaluative component built in. The concept of autonomy is itself an area of ethical debate in mental illness, precisely because, whatever incapacity mental illness causes, it surely has a direct impact on both the patient's capacity to be autonomous, and his or her experience of being autonomous. Further, in cases where mental illness is chronic (which is perhaps the more common situation), the patient's experience and capacity for autonomy will be bound up with his dependency relationships with his carers, both professional and personal. The traditional medical ethical view of autonomy may therefore be inappropriate.

What I also missed from this otherwise stimulating book was a section about the duties of psychiatrists generally. It might be illuminating to consider whether the duties of psychotherapists differ from the duties of more general psychiatrists. There is real uncertainty about the extent to which psychiatrists might have duties to third parties, and American lawyers and psychiatrists have experience of this; consider this quote from one of Szasz's papers: “Tomorrow's psychiatrists will be the gatekeepers of their community". Is this view tenable today, and in what circumstances? Where do the views of users' groups fit in relation to this view? These, and many other questions seem to me to be proper for a book looking at the ethical dilemmas in daily psychiatric practice.

In the final essay, Appelbaum suggests that, as a therapeutic strategy, deinstitutionalisation has had some unpleasant side effects. It has forced psychiatrists (both in the USA and the UK) to choose between two roles, both of which give rise to ethical tensions. The first role is as identifier and treater of mental illness; the second is that of public protector. The reality is that most psychiatrists carry both roles, and hastily change hats, depending on the situation, and the political wind, while trying to keep both hats in mind (so to speak). Edwards's choice of papers doesn't give much sense of how awful this can be to do. What his book does do is provide a solid introduction to some of 